\title{
Produção e soma térmica de cultivares de milho verde em duas semeaduras no verão
}

\author{
Jucimar Ferreira NEVES ${ }^{1 *}$, Sandra Mara Alves da Silva NEVES ${ }^{2}$, Santino SEABRA JÚNIOR ${ }^{2}$, \\ Rivanildo DALLACORT ${ }^{2}$
}

\author{
${ }^{1}$ Programa de Pós-Graduação em Agronomia, Universidade Federal da Grande Dourados, Dourados, MS, Brasil. \\ *E-mail: jucimarferreira@globo.com \\ ${ }^{2}$ Programa de Pós-Graduação em Ambiente e Sistemas de Produção Agrícola, Departamento de Agronomia, \\ Universidade do Estado de Mato Grosso, Tangará da Serra, MT, Brasil.
}

\begin{abstract}
Recebido em novembro/2018; Aceito em julho/2019.
RESUMO: O presente estudo objetivou avaliar a produtividade de cultivares de milho verde e definir a data de semeadura mais propícia ao desenvolvimento da cultura no município de Cáceres-MT. O experimento foi conduzido no delineamento de blocos casualizados, arranjados em esquema fatorial $5 \times 2$, com quatro repetições. Foram avaliados cinco cultivares de milho verde (AG 1051, AG 4051, BM 3061, RG 01 e Cativerde 02) cultivados em duas datas de semeadura (30 de dezembro de 2013 e 29 de janeiro de 2014). Avaliou-se a altura das plantas, altura da inserção da espiga, comprimento, diâmetro e peso de espigas empalhadas e despalhadas e a percentagem de espigas verdes comercializáveis, além do ciclo e a soma térmica em graus dia (GD) entre a emergência e a colheita da espiga verde. Verificou-se maior altura de planta e inserção de espiga nas plantas cultivadas em 30 de dezembro. Os híbridos BM 3061 e RG 01 foram colhidos com menor ciclo, e consequentemente, necessitaram de menor soma térmica. Os híbridos BM 3061, AG 1051 e AG 4051 foram os mais produtivos, sendo, portanto, mais indicados para o cultivo. A semeadura em dezembro proporcionou melhores resultados produtivos às plantas.
\end{abstract}

Palavras-chave: Zea mays; ciclo; graus dia; avaliação de cultivares.

\section{Production and thermal sum of cultivars of green corn in two sowings in the summer}

\begin{abstract}
The aims of the current study are to evaluate the yield of sweet corn cultivars and to define the most favorable sowing date for crop development in Cáceres County - MT. The experiment has followed a randomized block design, with factorial arrangement $5 \times 2$ and four repetitions. Five sweet corn cultivars (AG 1051, AG 4051, BM 3061, RG 01 and Cativerde 02) sown at two different sowing dates (December 30, 2013 and January 29,2014) were evaluated. The following parameters were assessed: plant height; ear insertion height; ear (with and without husk) length, diameter and weight; percentage of marketable green ears; cycle and thermal sum (in GD - degrees day) between green ear emergence and harvest. The highest plant height and ear insertion values were observed in plants grown on December 30. Hybrids 'BM 3061' and 'RG 01' were harvested in the shortest cycle and, consequently, they required lower thermal sum. BM 3061, AG 1051 and AG 4051 were the most productive hybrids; therefore, they were the most suitable for cultivation. Plants sown in December recorded the best yield rates.
\end{abstract}

Keywords: Zea mays; cycle; degree days; cultivar evaluation.

\section{INTRODUÇÃO}

O plantio do milho verde é muito comum no Brasil e vem aumentando de forma significativa em função de sua lucratividade se comparado ao milho em grãos secos, para atender à demanda crescente do mercado por espigas de melhor qualidade, é necessário aperfeiçoar o sistema de produção, buscando melhorias na produção e espigas em conformidade com as exigências do mercado consumidor (NASCIMENTO et al., 2017).

A produção de milho verde é de suma importância na valoração da mão-de-obra familiar pois contribui para a geração de empregos principalmente em pequenas e médias propriedades, onde as atividades de manejo e colheita são realizadas manualmente (PINHO et al., 2008).

O tamanho da espiga do milho verde é um fator preponderante na escolha do produto pelo consumidor, exigindo do agricultor a adoção de técnicas de implantação e manejo específicos para este segmento, cuja escolha de cultivares adaptáveis às condições edafoclimáticas da região é um fator decisivo, além de adotar populações de plantas e épocas de cultivo adequadas (VIEIRA et al., 2010). No mercado são poucas as ofertas de cultivares especificamente para milho verde, as informações e pesquisas sobre genótipos para este segmento são escassas, nesse sentido, são necessários estudos que possam desenvolver e avaliar o comportamento de novas cultivares.

Moraes et al. (2010), afirmam que a falta de informações sobre as cultivares disponíveis no mercado desestimulam a diversificação dos materiais genéticos empregados para produção de milho verde. Conforme Cardoso et al. (2011) é extremamente importante a identificação de novas cultivares de milho verde que possam ser introduzidas nos sistemas agrícolas familiares principalmente, pois o mercado, incluindo consumidores e indústria, tornam-se cada vez mais exigentes em relação às características das espigas, sobretudo o comprimento, diâmetro e peso. 
A data de plantio é um dos fatores relevantes na produtividade do milho verde, pois quando realizado em épocas desfavoráveis, as condições ambientais adequadas podem não ser alcançadas para cada estádio de desenvolvimento, causando prejuízos diretos à rentabilidade final do produto (ALBUQUERQUE et al., 2008).

Portanto, objetivou-se identificar as cultivares mais produtivas de milho verde e definir a melhor época de semeadura ao desenvolvimento da cultura no município de Cáceres-MT.

\section{MATERIAL E MÉTODOS}

O experimento foi conduzido na chácara Nossa Senhora Aparecida (propriedade particular), localizada no município de Cáceres-MT, região sudoeste de planejamento de Mato Grosso, localizado entre as latitudes $15^{\circ} 27^{\prime}$ e $17^{\circ} 37^{\prime}$ sul e as longitudes $57^{\circ} 00^{\prime}$ e $58^{\circ} 48^{\prime}$ oeste. O clima local é o tropical quente e úmido tipo Awa segundo classificação de Köppen. $\mathrm{O}$ município apresenta verão chuvoso, concentrando $62,68 \%$ dos $1335 \mathrm{~mm}$ de precipitação anual entre os meses de dezembro e março, janeiro é o mês mais chuvoso, a temperatura média anual é de $26,25^{\circ} \mathrm{C}$ (NEVES et al., 2011).

$\mathrm{O}$ experimento foi conduzido no delineamento em blocos casualizados, arranjados em esquema fatorial 5 x 2, com quatro repetições. Foram avaliados cinco cultivares de milho, descritos na literatura como indicados para o consumo "in natura", quais sejam: variedade semiprecoce Cativerde 02, os híbridos semiprecoces AG 1051 e AG 4051 e os híbridos precoces BM 3061 e RG 01, todos foram semeados em duas datas, sendo a primeira em 30 de dezembro de 2013 e a segunda em 29 de janeiro de 2014.

As parcelas experimentais foram constituídas de cinco linhas de cultivo com cinco metros cada, espaçadas entre si por $0,9 \mathrm{~m}$ e as plantas na linha por $0,25 \mathrm{~m}$ perfazendo uma população de 44.444 plantas ha $^{-1}$. As três linhas centrais foram consideradas como unidade demonstrativa útil, das quais foram avaliadas as dez plantas centrais de cada linha e suas respectivas espigas, totalizando uma unidade amostral de trinta plantas por parcela.

O preparo da área foi realizado no sistema convencional, com aração e gradagem do solo, em seguida foram realizados os sulcos de plantio devidamente adubados seguindo a recomendações de Cantarella; Raij (1997) mediante a interpretação da análise de solo da área. A adubação de cobertura foi realizada com macronutrientes, via solo composta por $150 \mathrm{~kg} \mathrm{ha}^{-1}$ de nitrogênio $(\mathrm{N})$ e $50 \mathrm{~kg} \mathrm{ha}^{-1}$ de potássio $\left(\mathrm{K}_{2} \mathrm{O}\right)$, utilizando respectivamente como fonte a ureia e o cloreto de potássio. Esta foi dividida em duas aplicações, a primeira quando as plantas apresentavam de três a quatro folhas definitivas e a segunda quando as plantas apresentavam nove folhas definitivas, aplicando 60 e $40 \%$ das doses, respectivamente.

O acompanhamento das variáveis meteorológicas foi realizado quanto a temperatura mínima, média e máxima registrada para cada ciclo de cultivo, os dados são oriundos da estação meteorológica localizada na área experimental de horticultura da Universidade do Estado de Mato Grosso em Cáceres. Além destes, o volume de precipitação também foi acompanhado através de um pluviômetro instalado no local do experimento. Com os dados de precipitação, temperatura do ar e classificação do solo foi realizado o balanço hídrico decendial de forma sequencial para a cultura conforme Rolim et al. (1998).
O cálculo da soma térmica em graus-dia (GD) foi realizado com base nos dados de temperatura, pelo método proposto por Ometto (1981), no qual é considerada a temperatura basal inferior e superior. Este é o método mais indicado para o cálculo de graus dia na cultura do milho em regiões com ocorrência de altas temperaturas (RENATO et al., 2013). Assumiu-se que o desenvolvimento das plantas foi constante entre a temperatura base inferior a $10^{\circ} \mathrm{C}$ e temperatura base superior a $32^{\circ} \mathrm{C}$. O cálculo foi realizado com base nas equações abaixo:

$\mathrm{TM}>\mathrm{TB}>\mathrm{Tm}>\mathrm{Tb}:$

$\mathrm{GD}=\frac{2(\mathrm{TM}-\mathrm{Tm})(\mathrm{Tm}-\mathrm{Tb})+(\mathrm{TM}-\mathrm{Tm})^{2}-(\mathrm{TM}-\mathrm{TB})}{2(\mathrm{TM}-\mathrm{TB})}$

$\mathrm{TB}>\mathrm{TM}>\mathrm{Tm}>\mathrm{Tb}:$

$\mathrm{GD}=\frac{(\mathrm{TM}-\mathrm{Tm})}{2}+\mathrm{Tm}-\mathrm{Tb}$

em que: $\mathrm{TM}=$ Temperatura máxima diária; $\mathrm{TB}=$ Temperatura basal superior; $\mathrm{Tm}=$ Temperatura mínima diária; $\mathrm{Tb}=$ Temperatura basal inferior.

A colheita foi realizada à medida que as espigas atingiam o ponto de milho verde, ou seja, quando mais de $50 \%$ das espigas atingiam o estádio de grão leitoso, com cerca de 70 a $80 \%$ de umidade.

Após a colheita, foram avaliadas as seguintes características: altura da planta e da inserção da espiga principal, comprimento, diâmetro e peso das espigas empalhadas e despalhadas e a percentagem de espigas verdes comercializáveis.

As percentagens de espigas verdes comercializáveis foram obtidas pelo número total de espigas que se enquadraram como comercializáveis e pelo total de espigas colhidas, considerando como espigas comerciais aquelas que apresentavam comprimento de granação superior a $15 \mathrm{~cm}$, livre de danos de insetos e diâmetro igual ou superior a $30 \mathrm{~mm}$ (ALBUQUERQUE et al., 2008).

Os dados foram submetidos à análise de variância e as médias comparadas entre si pelo teste de Scott-Knott.

\section{RESULTADOS}

Das características avaliadas, apenas para altura de inserção da espiga principal foi observada interação significativa entre os fatores cultivares e épocas de semeadura (Tabela 1). Na primeira época de semeadura a variedade Cativerde 02 e o híbrido AG 1051 proporcionaram as maiores médias para essa característica. Na segunda época de semeadura, além da variedade Cativerde 02, os híbridos AG 4051 e BM 3061 também evidenciaram as melhores médias para a característica em questão, diferindo das demais (Tabela 2). Ao comparar as datas de semeadura, todas as cultivares apresentaram maior altura de inserção da espiga na primeira data comparada à segunda.

Para as características de altura de plantas e peso das espigas empalhadas foi constatada diferença entre as datas de semeadura, obtendo-se maiores médias na primeira data de semeadura. Ao comparar as cultivares, a variedade Cativerde 02 juntamente com os híbridos BM 3061 e AG 1051 não diferiram entre si para a característica, apresentando superioridade em relação aos demais (Tabela 3). 
Tabela 1. Resumo da análise de variância de cinco cultivares de milho verde cultivados em duas datas de semeadura. Table 1. Summary of the analysis of variance of five cultivars of green corn grown in two seeding dates.

\begin{tabular}{lccccc}
\hline \multirow{2}{*}{ FV } & \multicolumn{5}{c}{ QUADRADO MÉDIO } \\
\cline { 2 - 5 } & G.L & AP & AIE & PEE & CEE \\
\hline Blocos & 3 & $54,68367^{\text {ns }}$ & $7,75275^{\text {ns }}$ & $257,21075^{\text {ns }}$ & $0,75573^{\text {ns }}$ \\
D.S & 1 & $20286,01600^{* *}$ & $3480,09025^{* *}$ & $13042,93225^{* *}$ & $5,22006^{\text {ns }}$ \\
Cult & 4 & $762,89978^{* *}$ & $357,08172^{* *}$ & $1469,52209^{* *}$ & $10,77647^{* *}$ \\
D.S*Cult & 4 & $123,64241^{\text {ns }}$ & $196,47509^{* *}$ & $146,96459^{\text {ns }}$ & $4,80803^{\text {ns }}$ \\
Resíduo & 27 & 63,81094 & 32.03548 & 381.85802 & 2,89406 \\
CV (\%) & & 3,14 & 5,24 & 5,80 & 6,37 \\
\hline FV & DEE & CED & DED & PED & EC \\
\hline Blocos & $2,48183^{\text {ns }}$ & $0,15159^{\text {ns }}$ & $0.09308^{\text {ns }}$ & $106,43775^{\text {ns }}$ & $88,39972^{\text {ns }}$ \\
D.S & $18,63225^{* *}$ & $39,90006^{* *}$ & $0,28056^{\text {ns }}$ & $1184,83225^{* *}$ & $390,56250^{* *}$ \\
Cult & $10,74022^{* *}$ & $3,24841^{* *}$ & $10,51338^{* *}$ & $1164,59834^{* *}$ & $1189,32473^{* *}$ \\
D.S*Cult & $0,71334^{\text {ns }}$ & $0,85941^{\text {ns }}$ & $0,64544^{\text {ns }}$ & $148,27022^{\text {ns }}$ & $129,34723^{\text {ns }}$ \\
Resíduo & 1,89674 & 0,37277 & 0,68307 & 92,86233 & 57,28254 \\
CV (\%) & 2,57 & 3,41 & 1,99 & 4,67 & 9,16 \\
\hline
\end{tabular}

FV - Fonte da variação; AP - Altura de plantas; AIE - Altura da inserção da espiga; PEE - Peso da espiga empalhada; CEE - Comprimento da espiga empalhada; DEE - Diâmetro da espiga empalhada; CED - Comprimento da espiga despalhada; DED - Diâmetro da espiga despalhada; PED - Peso da espiga despalhada; EC - Percentagem de espigas comerciais.

ns - não significativo; ${ }^{* *}$ - significativo a $5 \%$ pelo teste $\mathrm{F}$.

FV-source of variation; AP-Plant height; AIE-Height of insertion of the cob; PEE-weight weight of the cob without straw ; CEE-length of the cob without straw; DEE-diameter of the cob without straw; CED-Length of cob without straw; DED-diameter of cob without straw; PED-weight of cob without straw; EC-percentage of commercial green cob.

NS -not significant; ** significant at 5\%-by $\mathrm{F}$.

Tabela 2. Altura de inserção da espiga principal de cinco cultivares de milho verde em duas datas de semeadura.

Table 2. Height of insertion of the cob five main cultivars of green corn in two seeding dates.

\begin{tabular}{lcc}
\hline \multirow{2}{*}{ Cultivares } & \multicolumn{2}{c}{ Altura $(\mathrm{cm})$} \\
\cline { 2 - 3 } & $1^{\circ}$ Semeadura & $2^{\circ}$ Semeadura \\
\hline Cativerde 02 & 130,5 a A & 108,2 a B \\
RG 01 & 111,0 b A & 92,3 b B \\
BM 3061 & 110,7 b A & 100,0 a B \\
AG 1051 & 124,0 a A & 90,9 b B \\
AG 4051 & 110,7 b A & 102,4 a B \\
\hline CV & $5,24 \%$ & \\
\hline
\end{tabular}

Médias antecedidas pela mesma letra maiúscula na linha e minúscula na coluna não diferem entre si pelo teste de Scott-Knott, em nível de 5\% de probabilidade.

Means followed by the same letter, lower case and in line in the column do not differ by Scott-Knott test at $5 \%$ probability.

Tabela 3. Altura de plantas (AP), peso de espiga empalhada (PEE), comprimento de espiga empalhada (CEE) e diâmetro de espiga empalhada (DEE) de cinco cultivares de milho verde semeadas em duas épocas de semeadura.

Table 3. Plant height (AP), weight of the cob without straw (PEE), length of the cob without straw (CEE) and diameter of the cob without straw (DEE) of five cultivars of green corn sown in two seasons of seeding.

\begin{tabular}{lcccc}
\hline Características & AP $(\mathrm{cm})$ & PEE $(\mathrm{g})$ & CEE $(\mathrm{cm})$ & DEE $(\mathrm{mm})$ \\
\hline $1^{\circ}$ Semeadura & $247,0 \mathrm{a}$ & $349,7 \mathrm{a}$ & $27,1 \mathrm{a}$ & $52,9 \mathrm{~b}$ \\
$2^{\circ}$ Semeadura & $202,0 \mathrm{~b}$ & $313,5 \mathrm{~b}$ & $26,4 \mathrm{a}$ & $54,2 \mathrm{a}$ \\
\hline Cativerde 02 & $236,0 \mathrm{a}$ & $317,5 \mathrm{~b}$ & $27,5 \mathrm{a}$ & $51,7 \mathrm{~b}$ \\
RG 01 & $211,0 \mathrm{~b}$ & $318,0 \mathrm{~b}$ & $25,7 \mathrm{~b}$ & $53,8 \mathrm{a}$ \\
BM 3061 & $229,0 \mathrm{a}$ & $348,8 \mathrm{a}$ & $28,3 \mathrm{a}$ & $53,4 \mathrm{a}$ \\
AG 1051 & $228,0 \mathrm{a}$ & $336,0 \mathrm{a}$ & $26,3 \mathrm{~b}$ & $54,0 \mathrm{a}$ \\
AG 4051 & $219,0 \mathrm{~b}$ & $337,6 \mathrm{a}$ & $25,7 \mathrm{~b}$ & $54,8 \mathrm{a}$ \\
\hline CV \% & 3,14 & 5,80 & 6,37 & 2,57 \\
\hline
\end{tabular}

Médias antecedidas pela mesma letra minúscula na coluna não diferem entre si pelo teste de Scott-Knott, em nível de 5\% de probabilidade.

Means followed by the same letter, lower case and in line in the column do not differ by Scott-Knott test at $5 \%$ probability.
Para diâmetro de espiga empalhada as maiores médias foram observadas para as plantas cultivadas na segunda época de semeadura, inverso do que foi verificado para peso e comprimento destas. A variedade Cativerde 02 proporcionou a menor média de diâmetro da espiga, diferindo dos demais materiais avaliados.

As plantas cultivadas na primeira época de semeadura apresentaram as maiores médias, para as características comprimento de espiga despalhada, peso de espiga despalhada e percentagem de espigas comerciais, porém, o diâmetro da espiga despalhada não foi influenciado pela época de semeadura. Em relação às cultivares, o maior comprimento de espiga foi observado no híbrido BM 3061 e para o diâmetro houve destaque para os híbridos AG 1051 e AG 4051. Os híbridos BM 3061, AG 1051 e AG 4051 se destacaram em relação ao peso da espiga despalhada (Tabela 4).

Tabela 4. Comprimento de espiga despalhada (CED), diâmetro de espiga despalhada (DED), peso de espiga despalhada (PED) e percentagem de espigas verdes comerciais (EC) de cinco cultivares de milho verde semeadas em duas épocas de semeadura.

Table 4. Length of cob without straw (CED), diameter of cob without straw (DED), weight of cob without straw (PED) and percentage of commercial green cob (EC) of five cultivars of green corn sowed at two sowing times.

\begin{tabular}{lcccc}
\hline Características & CED $(\mathrm{cm})$ & DED $(\mathrm{mm})$ & PED $(\mathrm{g})$ & EC $(\%)$ \\
\hline $1^{\circ}$ Semeadura & $18,9 \mathrm{a}$ & $41,5 \mathrm{a}$ & $211,7 \mathrm{a}$ & $85,8 \mathrm{a}$ \\
$2^{\circ}$ Semeadura & $16,9 \mathrm{~b}$ & $41,6 \mathrm{a}$ & $200,8 \mathrm{~b}$ & $79,6 \mathrm{~b}$ \\
\hline Cativerde 02 & $17,9 \mathrm{~b}$ & $39,8 \mathrm{c}$ & $191,0 \mathrm{~b}$ & $67,0 \mathrm{~b}$ \\
RG 01 & $17,2 \mathrm{~b}$ & $41,5 \mathrm{~b}$ & $196,8 \mathrm{~b}$ & $72,0 \mathrm{~b}$ \\
BM 3061 & $18,9 \mathrm{a}$ & $41,4 \mathrm{~b}$ & $220,2 \mathrm{a}$ & $93,1 \mathrm{a}$ \\
AG 1051 & $17,7 \mathrm{~b}$ & $42,8 \mathrm{a}$ & $209,6 \mathrm{a}$ & $90,0 \mathrm{a}$ \\
AG 4051 & $17,7 \mathrm{~b}$ & $42,9 \mathrm{a}$ & $213,7 \mathrm{a}$ & $91,1 \mathrm{a}$ \\
\hline CV \% & 3,41 & 1,99 & 4,67 & 9,16 \\
\hline
\end{tabular}

Médias antecedidas pela mesma minúscula na coluna não diferem entre si pelo teste de Scott-Knott, em nível de 5\% de probabilidade.

Means followed by the same letter, lower case and in line in the column do not differ by Scott-Knott test at 5\% probability. 
Para o peso de espigas despalhadas foi observada maior média no cultivo dos híbridos BM 3061, AG 4051 e AG 1051, diferindo dos demais (Tabela 4).

Os híbridos BM 3061, AG 4051 e AG 1051 destacaram-se quanto à percentagem de espigas verdes comerciais, não diferindo entre si, da mesma forma que a variedade Cativerde e o híbrido RG 01 também não diferiram, contudo apresentando médias inferiores aos materiais citados anteriormente (Tabela 4).

Quanto ao ciclo, os genótipos podem ser divididos em dois grupos, o primeiro pertinente aos híbridos de ciclo precoce BM 3061 e RG 01 que, para produzir espigas verdes em seu estado de grão leitoso, necessitaram de 66 dias após a semeadura, o segundo, relativo ao grupo semiprecoce composto pelos híbridos AG 1051, AG 4051 e a variedade Cativerde 02 necessitaram de 70 dias, ambos na primeira data de semeadura. Estas datas corresponderam ao equivalente a 1082,82 graus dia para os híbridos precoces e 1157,68 no caso dos semiprecoces (Tabela 5)

$\mathrm{Na}$ segunda data de semeadura, o ciclo dos híbridos precoces correspondeu a 72 dias para a colheita, totalizando 1178 graus dia a contar após a emergência e os híbridos semiprecoces somaram 76 dias, acumulando após a emergência 1248 graus dia (Tabela 6).

Tabela 5. Soma térmica (Graus dia) acumulada pelos genótipos de milho verde entre a emergência e a colheita da espiga verde em duas datas de semeadura.

Table 5. Thermal sum (Degrees day) accumulated by genotypes of green corn between emergence and green ear harvesting in two sowing dates.

\begin{tabular}{|c|c|c|c|c|c|c|c|c|c|c|c|c|c|}
\hline \multicolumn{14}{|c|}{$1^{\circ}$ Semeadura } \\
\hline \multirow[t]{2}{*}{ DAS } & \multicolumn{6}{|c|}{$\begin{array}{l}\text { CULTIVAR } \\
\text { Número de folhas }\end{array}$} & \multirow[t]{2}{*}{ DAS } & \multirow[t]{2}{*}{ GD } & \multicolumn{5}{|c|}{$\begin{array}{c}\text { CULTIVAR } \\
\text { Número de folhas }\end{array}$} \\
\hline & & I & II & III & IV & V & & & I & II & III & IV & V \\
\hline 0 & 0 & 0 & 0 & 0 & 0 & 0 & 30 & 462,65 & 7 & 7 & 7 & 7 & 7 \\
\hline 5 & 20,00 & E & E & E & E & $\mathrm{E}$ & 31 & 479,96 & 8 & 8 & 7 & 7 & 7 \\
\hline 6 & 38,15 & 0 & 0 & 0 & 0 & 0 & 32 & 497,59 & 8 & 8 & 7 & 7 & 7 \\
\hline 7 & 56,74 & 0 & 0 & 0 & 0 & 0 & 33 & 514,77 & 8 & 8 & 7 & 8 & 7 \\
\hline 8 & 75,85 & 0 & 0 & 0 & 0 & 0 & 34 & 532,67 & 8 & 8 & 8 & 8 & 8 \\
\hline 9 & 93,39 & 1 & 1 & 1 & 1 & 1 & 35 & 551,17 & 9 & 9 & 8 & 8 & 8 \\
\hline 10 & 111,88 & 1 & 1 & 1 & 1 & 1 & 36 & 569,58 & 9 & 9 & 8 & 8 & 8 \\
\hline 11 & 129,98 & 1 & 1 & 1 & 1 & 1 & 37 & 585,33 & 9 & 9 & 8 & 9 & 9 \\
\hline 12 & 148,52 & 2 & 2 & 2 & 2 & 2 & 38 & 602,32 & 9 & 9 & 9 & 9 & 9 \\
\hline 13 & 167,01 & 2 & 2 & 2 & 2 & 2 & 39 & 620,51 & 10 & 10 & 9 & 9 & 9 \\
\hline 14 & 184,88 & 3 & 3 & 2 & 2 & 2 & 40 & 637,43 & 10 & 10 & 9 & 9 & 9 \\
\hline 15 & 201,46 & 3 & 3 & 2 & 3 & 3 & 41 & 655,37 & 10 & 10 & 9 & 9 & 9 \\
\hline 16 & 219,94 & 3 & 3 & 3 & 3 & 3 & 42 & 674,41 & 10 & 10 & 10 & 10 & 10 \\
\hline 17 & 237,82 & 4 & 4 & 3 & 3 & 3 & 43 & 691,27 & 11 & 11 & 10 & 10 & 10 \\
\hline 18 & 255,78 & 4 & 4 & 3 & 4 & 3 & 44 & 709,32 & 11 & 11 & 10 & 10 & 10 \\
\hline 19 & 273,89 & 4 & 4 & 4 & 4 & 4 & 45 & 726,55 & 12 & 12 & 10 & 10 & 10 \\
\hline 20 & 292,82 & 4 & 4 & 4 & 4 & 4 & 46 & 742,73 & 12 & 12 & 11 & 11 & 11 \\
\hline 21 & 311,29 & 5 & 5 & 5 & 5 & 5 & 47 & 759,59 & 12 & 12 & 11 & 11 & 11 \\
\hline 22 & 326,91 & 5 & 5 & 5 & 5 & 5 & 48 & 776,82 & VT & VT & 12 & VT & 12 \\
\hline 23 & 343,71 & 5 & 5 & 5 & 5 & 5 & $* 49$ & 793,76 & & & VT & & VT \\
\hline 24 & 361,26 & 6 & 6 & 5 & 5 & 5 & $* 66$ & 1082,82 & $\mathrm{C}$ & $\mathrm{C}$ & & & \\
\hline 25 & 378,07 & 6 & 6 & 5 & 6 & 5 & 67 & 1101,51 & & & & & \\
\hline 26 & 395,28 & 6 & 6 & 6 & 6 & 6 & 68 & 1119,99 & & & & & \\
\hline 27 & 412,80 & 7 & 7 & 6 & 6 & 6 & 69 & 1138,49 & & & & & \\
\hline 28 & 429,08 & 7 & 7 & 6 & 6 & 6 & 70 & 1157,68 & & & $\mathrm{C}$ & $\mathrm{C}$ & $\mathrm{C}$ \\
\hline 29 & 445,61 & 7 & 7 & 6 & 7 & 6 & & & & & & & \\
\hline
\end{tabular}

DAS = dias após a semeadura; GD = graus-dia;E = Emergência; VT = Pendoamento; C = Data da Colheita; Cultivares: I = BM 3061, II RG 01, III AG 1051, $\mathrm{IV}=\mathrm{AG} 4051, \mathrm{~V}=$ Cativerde. * Período entre o pendoamento e a colheita não monitorado.

$\mathrm{DAS}=$ days after sowing; $\mathrm{GD}=$ degree days; $\mathrm{E}=$ Emergency; $\mathrm{VT}=$ emergence of the tassel; $\mathrm{C}=$ harvest date; $\mathrm{I}=\mathrm{BM} 3061 ; \mathrm{II}=\mathrm{RG} 01 ; \mathrm{III}=\mathrm{AG} 1051 ; \mathrm{IV}=\mathrm{AG}$ 4051; V= Cativerde; * Period between emergence of the tassel and harvesting not monitored.

\section{DISCUSSÃO}

A altura de inserção da espiga foi inferior à observada por Favarato et al. (2016), avaliando o híbrido AG $1051 \mathrm{em}$ Domingos Martins-ES, em sistema plantio direto. Avaliando as cultivares Cativerde 02, BM 3061, AG 1051 e AG 4051, Cardoso et al. (2011) também relataram, em Teresina-PI, $134,5 \mathrm{~cm}$ de média para inserção da espiga, superior às médias observadas para as mesmas cultivares no estudo em questão, todavia, ambos os autores citados utilizaram 50 mil plantas por hectare, superior à utilizada neste trabalho, o que pode ter favorecido o crescimento em altura das plantas no estudo dos mesmos.

Com relação à altura de plantas, Moraes et al. (2010) ao avaliarem oito cultivares de milho verde em três municípios do estado de São Paulo observaram para as cultivares AG 1051, AG 4051, BM 3061 e Cativerde 02 alturas de plantas de 201,$9 ; 215,8 ; 205,5$ e 207,8 cm respectivamente, resultados estes abaixo dos obtidos no experimento em questão. No entanto, essa diferença deve-se ao fato que os autores realizaram o estudo no período de safrinha, com semeadura em março, que pode ter desfavorecido o desenvolvimento das plantas devido à redução nas precipitações, assim como observado para este estudo, no qual houve redução na altura das plantas com o atraso na semeadura.

O híbrido AG 1051 apresentou maior peso de espiga empalhada no trabalho de Pinho et al. (2008) em Sete LagoasMG quando comparado aos dados deste estudo e aos demais genótipos avaliados pelos mesmos, apresentando média de 
420,15 g, demonstrando assim, a qualidade do material independentemente do local. As demais cultivares avaliadas pelos autores acima citados apresentaram entre 307,34 e 316,48 g espiga $^{-1}$, resultado semelhante ao deste estudo.

No entanto, os genótipos avaliados neste estudo apresentaram valores superiores aos encontrados por Grigulo et al. (2011) no município de Tangará da Serra-MT, que obtiveram médias variando de 170,5 e $245,0 \mathrm{~g}$ espiga $^{-1}$, e para o híbrido AG 1051215,1 g espiga $^{-1}$, bem inferior aos obtidos neste estudo, diferença que pode estar relacionada às práticas de manejo adotadas, visto que o estudo foi realizado em regiões próximas e com datas de semeadura semelhantes.

Tabela 6. Soma térmica (Graus dia) acumulada pelos genótipos de milho verde entre a emergência e a colheita da espiga verde em duas datas de semeadura.

Table 6. Thermal sum (Degrees day) accumulated by genotypes of green corn between emergence and green ear harvesting in two sowing dates.

\begin{tabular}{|c|c|c|c|c|c|c|c|c|c|c|c|c|c|}
\hline \multicolumn{14}{|c|}{$2^{\circ}$ Semeadura } \\
\hline \multirow[t]{2}{*}{ DAS } & \multicolumn{6}{|c|}{$\begin{array}{l}\text { CULTIVAR } \\
\text { Número de folhas }\end{array}$} & \multirow[t]{2}{*}{ DAS } & \multirow[t]{2}{*}{ GD } & \multicolumn{5}{|c|}{$\begin{array}{c}\text { CULTIVAR } \\
\text { Número de folhas }\end{array}$} \\
\hline & & I & II & III & IV & $\mathrm{V}$ & & & I & II & III & IV & $\mathrm{V}$ \\
\hline 0 & 0 & 0 & 0 & 0 & 0 & 0 & 32 & 460,70 & 8 & 8 & 7 & 7 & 7 \\
\hline 5 & 0 & 0 & 0 & 0 & 0 & 0 & 33 & 478,00 & 8 & 8 & 7 & 7 & 7 \\
\hline 6 & 18,51 & E & E & E & E & E & 34 & 496,03 & 8 & 8 & 7 & 8 & 7 \\
\hline 7 & 36,92 & 0 & 0 & 0 & 0 & 0 & 35 & 514,36 & 9 & 9 & 8 & 8 & 8 \\
\hline 8 & 52,66 & 0 & 0 & 0 & 0 & 0 & 36 & 532,40 & 9 & 9 & 8 & 8 & 8 \\
\hline 9 & 69,65 & 1 & 1 & 1 & 1 & 1 & 37 & 550,15 & 9 & 9 & 8 & 8 & 8 \\
\hline 10 & 87,84 & 1 & 1 & 1 & 1 & 1 & 38 & 568,84 & 10 & 10 & 9 & 9 & 9 \\
\hline 11 & 104,76 & 1 & 1 & 1 & 1 & 1 & 39 & 587,33 & 10 & 10 & 9 & 9 & 9 \\
\hline 12 & 122,71 & 2 & 2 & 2 & 2 & 2 & 40 & 605,83 & 10 & 10 & 9 & 9 & 9 \\
\hline 13 & 141,75 & 2 & 2 & 2 & 2 & 2 & 41 & 625,02 & 11 & 11 & 10 & 10 & 10 \\
\hline 14 & 158,61 & 2 & 2 & 2 & 2 & 2 & 42 & 643,94 & 11 & 11 & 10 & 10 & 10 \\
\hline 15 & 176,65 & 3 & 2 & 2 & 2 & 2 & 43 & 658,46 & 11 & 11 & 10 & 10 & 10 \\
\hline 16 & 193,88 & 3 & 3 & 3 & 3 & 3 & 44 & 676,14 & 12 & 12 & 10 & 10 & 10 \\
\hline 17 & 210,06 & 3 & 3 & 3 & 3 & 3 & 45 & 694,64 & 12 & 12 & 10 & 10 & 10 \\
\hline 18 & 226,93 & 3 & 3 & 3 & 3 & 3 & 46 & 712,98 & 12 & 12 & 10 & 11 & 10 \\
\hline 19 & 244,15 & 4 & 3 & 3 & 3 & 3 & 47 & 731,16 & 13 & 13 & 11 & 11 & 11 \\
\hline 20 & 261,09 & 4 & 4 & 3 & 3 & 3 & 48 & 748,93 & 13 & 13 & 11 & 11 & 11 \\
\hline 21 & 279,46 & 4 & 4 & 4 & 4 & 4 & 49 & 767,14 & 13 & 13 & 12 & 12 & 12 \\
\hline 22 & 295,25 & 4 & 4 & 4 & 4 & 4 & 50 & 785,84 & 14 & 14 & 12 & 12 & 12 \\
\hline 23 & 312,90 & 5 & 5 & 4 & 4 & 4 & 51 & 804,67 & VT & VT & 12 & 12 & 12 \\
\hline 24 & 327,48 & 5 & 5 & 4 & 4 & 4 & 52 & 823,43 & & & 12 & 12 & 12 \\
\hline 25 & 344,75 & 5 & 5 & 5 & 5 & 5 & $* 53$ & 842,26 & & & VT & VT & VT \\
\hline 26 & 360,59 & 6 & 6 & 5 & 5 & 5 & $* 72$ & 1178,28 & $\mathrm{C}$ & $\mathrm{C}$ & & & \\
\hline 27 & 375,15 & 6 & 6 & 5 & 5 & 5 & 73 & 1196,52 & & & & & \\
\hline 28 & 391,20 & 6 & 6 & 6 & 6 & 6 & 74 & 1214,93 & & & & & \\
\hline 29 & 409,54 & 7 & 7 & 6 & 6 & 6 & 75 & 1233,48 & & & & & \\
\hline 30 & 427,44 & 7 & 7 & 6 & 6 & 6 & 76 & 1248,71 & & & $\mathrm{C}$ & $\mathrm{C}$ & $\mathrm{C}$ \\
\hline 31 & 444,43 & 7 & 7 & 7 & 7 & 7 & & & & & & & \\
\hline
\end{tabular}

DAS = dias após a semeadura; GD = graus-dia; $\mathrm{E}=$ Emergência; VT = Pendoamento; $\mathrm{C}=$ Data da Colheita; Cultivares: I = BM 3061, II RG 01, III AG 1051, $\mathrm{IV}=\mathrm{AG} 4051, \mathrm{~V}=$ Cativerde. $*$ Período entre o pendoamento e a colheita não monitorado.

$\mathrm{DAS}=$ days after sowing; $\mathrm{GD}=$ degree days; $\mathrm{E}=$ Emergency; VT= emergence of the tassel; $\mathrm{C}=$ harvest date; $\mathrm{I}=\mathrm{BM} 3061 ; \mathrm{II}=\mathrm{RG} 01 ; \mathrm{III}=\mathrm{AG} 1051 ; \mathrm{IV}=\mathrm{AG}$ 4051; V=Cativerde; * Period between emergence of the tassel and harvesting not monitored.

A produtividade de espigas empalhadas, segundo Rodrigues et al. (2011), é o principal fator e suficiente para definir a produção comercial de um genótipo. Se levarmos em conta o número de espigas ha-1 e o peso de espigas empalhadas, poderíamos estimar produtividade entre 13.977 e $15.502 \mathrm{~kg} \mathrm{ha}$ ${ }^{1}$ para o experimento em questão, o que seria semelhante ao observado por PAIVA et al. (2012) em Baraúna-RN nas maiores doses de fósforo $\left(120 \mathrm{~kg} \mathrm{ha}^{-1} \mathrm{de}^{\left.\mathrm{P}_{2} \mathrm{O}_{5}\right)}\right.$ e nitrogênio (120 kg ha ${ }^{-1}$ de N) aplicada pelos mesmos.

Apesar de todos os genótipos avaliados neste estudo apresentarem medidas de comprimento e diâmetro suficientes para serem classificadas como comerciais, Cardoso et al. (2011) observaram em Teresina-PI, médias superiores às apresentadas neste estudo, com 19,5 $\mathrm{cm}$ e $46,8 \mathrm{~mm}$ para quatro dos cinco genótipos presentes neste experimento, das mesma forma que Moraes et al. (2010) com $18 \mathrm{~cm}$ e 45,1 mm para comprimento e diâmetro, respectivamente.

No entanto, as médias observadas neste experimento podem ser consideradas satisfatórias e comparadas às obtidas por Santos et al. (2010) e Rodrigues et al. (2011) nos estados do Paraná e Minas Gerais, com médias de 16,7 e $15,7 \mathrm{~cm}$ para comprimento e 44 e $41 \mathrm{~mm}$ para diâmetro, respectivamente. Todavia, os dois últimos citados são estudos desenvolvidos com cultivares diferentes aos deste, o que pressupõe que a diferença pode estar relacionada aos genótipos utilizados.

Os resultados para peso de espigas despalhadas foram superiores aos observados por Moraes et al. (2010) no estado de São Paulo, com melhores resultados obtidos com o híbrido BM 3061, com média de 143g planta ${ }^{-1}$, ressalta-se que os mesmos trabalharam no cultivo em safrinha. Para as mesmas cultivares, Cardoso et al. (2011) encontraram médias variando entre 189 e $261 \mathrm{~g}$ por espiga ${ }^{-1}$ em Teresina-PI em cultivo de verão.

Para o índice de espigas comerciais, Moraes et al. (2010) observaram resultado semelhante aos deste experimento apenas para Cativerde 02 e inferiores para os demais híbridos, principalmente BM 3061, com apenas $72,5 \%$ das espigas comerciais. O baixo índice de espigas comerciais observado 
pelos autores pode ser atribuído ao critério de tamanho adotado na metodologia, que definiu como parâmetro para classificação das espigas como comerciais aquelas com tamanho igual ou superior a $17 \mathrm{~cm}$. Trabalhando com genótipos diferentes aos desta pesquisa, Vieira et al. (2010) constataram resultados semelhantes entre 78 e $92 \%$, assim como Grigulo et al. (2011) com resultados entre 78 e $97 \%$ de espigas comerciais.

Cardoso et al. (2011) notaram resultados semelhantes para os genótipos BM 3061, AG 4051 e AG 1051 com melhores índices no experimento em questão, apesar disso a média observada pelos mesmos para a variedade Cativerde 02 foi $29 \%$ superior à obtida neste estudo, diferença que pode estar ligada à adaptação desta variedade às condições locais, visto que o trabalho dos mesmos foi desenvolvido em Teresina-PI, em que a temperatura média anual é $28^{\circ} \mathrm{C}$ segundo Rocha et al. (2012), $1,75^{\circ} \mathrm{C}$ mais alta.

A diferença observada no ciclo das variedades está relacionada à especificidade de cada material, no caso das cultivares, e na época de semeadura, visto que, as características das variáveis climáticas as quais as plantas foram submetidas estão sujeitas a mudanças em um curto espaço de tempo, podendo influenciar diretamente nas plantas e no rendimento final da cultura. Observou-se o aumento em seis dias entre as cultivares da primeira para a segunda data de semeadura no ciclo.

Grigulo et al. (2011), observaram média de 80 dias com o híbrido AG 1051 em Tangará da Serra-MT e em três municípios do estado de São Paulo Moraes et al. (2010) avaliando as mesmas cultivares do experimento em questão, observaram médias superiores, entre 92 e 110 dias, o que pode ser atribuído às diferenças das variáveis climáticas regionais, que alteram o número de dias necessários para as plantas atingirem unidades calóricas suficientes para mudança das fases de desenvolvimento. Corroborando, Fenner et al. (2015) estudando o ciclo e a necessidade hídrica do milho em três municípios de Mato Grosso concluíram que, comparado aos municípios de Tangará da Serra-MT e Sorriso-MT, CáceresMT apresenta maior demanda evaporativa e temperatura média comparado aos demais, o que resulta no encurtamento do ciclo ocasionado pelo maior acúmulo térmico diário.

A precipitação observada foi de 610 e $700 \mathrm{~mm}$ para o primeiro e segundo ciclo de cultivo respectivamente, valores suficientes para o desenvolvimento da cultura segundo Bergamashi et al. (2004), que afirmam que no Brasil entre 400 a $700 \mathrm{~mm}$ são suficientes, desde que não falte água no período crítico caracterizado pelas fases de embonecamento e enchimento de grãos, na qual o déficit hídrico antes ou durante estas fases podem causar redução no rendimento, os mesmos reforçam ainda, que o milho expressa alta sensibilidade à deficiência hídrica, manifestada principalmente em relação à época de semeadura.

Observou-se que a precipitação ocorreu com grande frequência e bem distribuída no primeiro ciclo de cultivo, enquanto que no segundo esteve presente de forma mais intensa, principalmente nos primeiros 25 dias de cultivo, e caracterizada por duas precipitações intensas de 100 e $55 \mathrm{~mm}$ (Figura 1), diminuindo drasticamente no restante do ciclo, o que pode ter influenciado no não suprimento das exigências hídricas no período crítico da cultura.

As variações de armazenamento de água no perfil do solo para épocas de semeadura acompanharam a dinâmica observada na precipitação refletindo em diferentes teores de acúmulo hídrico entre a primeira e a segunda data de semeadura (Figura 2).

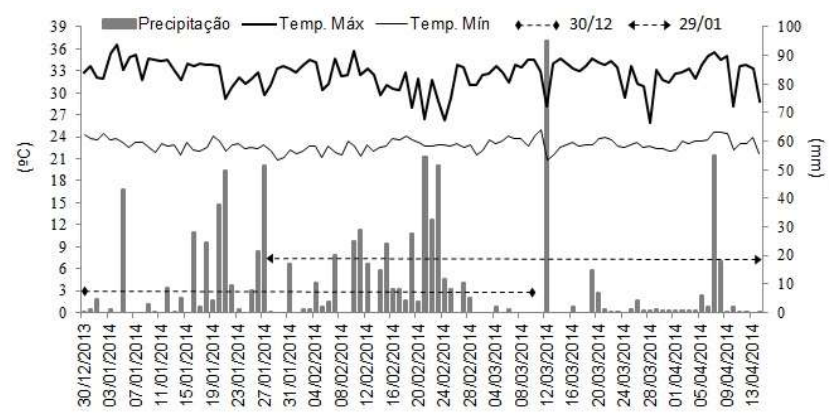

Figura 1. Temperatura máxima, mínima e volume de precipitação para as duas datas de semeadura do milho verde em Cáceres-MT.

Figure 1. Maximum temperature, minimum and volume of precipitation for the two dates of sowing of the green corn in CáceresMT.

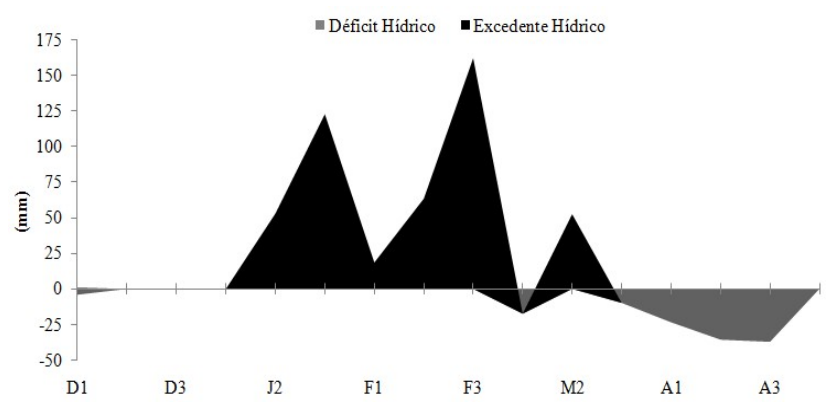

Figura 2. Balanço hídrico decendial de forma sequencial para o cultivo de milho verde em Cáceres-MT.

Figure 2. Water balance decendial in sequence for green corn cultivation in Cáceres-MT.

Pode-se observar que na semeadura em 30 de dezembro ocorreu acúmulo de água no solo com balanço positivo durante todo o ciclo da cultura, com leve redução no primeiro decêndio de março, favorecendo a colheita. Para a semeadura em 29 de janeiro ocorreu déficit hídrico para a cultura na fase crítica, observado no último decêndio do mês de março e no início do mês de abril, caracterizado pelas fases de pendoamento ao enchimento de grãos, consideradas críticas ao desenvolvimento da cultura. Embasado em Bergamaschi et al. (2004), esse déficit hídrico, pode explicar as diferenças produtivas e morfológicas das plantas observadas entre as duas datas de semeadura.

\section{CONCLUSÕES}

A primeira data de semeadura, em dezembro, proporcionou melhores condições climáticas ao desenvolvimento das plantas e a produção de milho verde. Os híbridos BM 3061, AG 1051 e AG 4051 foram os mais produtivos e são os mais recomendados para as condições em questão. Os híbridos BM 3061 e RG 01 necessitaram de menor número de dias para o ciclo e, consequentemente, menor soma térmica para atingir o estágio de espigas verdes.

\section{AGRADECIMENTOS}

O presente trabalho foi realizado com apoio da Coordenação de Aperfeiçoamento de Pessoal de Nível Superior - Brasil (CAPES) - Código de Financiamento 001 


\section{REFERÊNCIAS}

ALBUQUERQUE, C. J. B.; VON PINHO, R. G.; SILVA, R. Produtividade de híbridos de milho verde experimentais e comerciais. Bioscience Journal, Uberlândia, v. 24, n. 2, p. 69-76, 2008.

BERGAMASCHI, H.; DALMAGO, G. A.; BERGONCI, J. I.; BIANCHI, C. A. M.; MULLER, A. G.; COMIRAN, F.; HECKLER, B. M. M. Distribuição hídrica no período crítico do milho e produção de grãos. Pesquisa Agropecuária Brasileira, Brasília, v. 39, n. 9, p. 831-839, 2004. DOI: http://dx.doi.org/10.1590/S0100204X2004000900001

CANTARELLA, H.; RAIJ, B. V. Milho verde e milho doce. In: RAIJ, B. V.; CANTARELLA, H.; QUAGGIO, J. A.; FURLANI, A. M. C. Recomendação de Adubação e Calagem para o Estado de São Paulo. 2. ed. Campinas, Instituto Agronômico, 1997. 285 p. (Boletim 100).

CARDOSO, M. J.; RIBEIRO, V. Q.; MELO, F. B. Performance de cultivares de milho-verde no Município de Teresina, Piauí. Teresina: EMBRAPA MEIO-NORTE, 2011. 4 p. (Comunicado Técnico, n. 227).

FAVARATO, L. F.; SOUZA, J. L.; GALVÃO, J. C. C.; SOUZA, C. M.; GUARCONI, R. C.; BALBINO, J. M. S. Crescimento e produtividade do milho-verde sobre diferentes coberturas de solo no sistema plantio direto orgânico, Bragantia, Campinas, v. 75, n. 4, p. 497-506, 2016. DOI: http://dx.doi.org/10.1590/1678-4499.549

FENNER, W.; DALLACORT, R.; MOREIRA, P. S. P.; QUEIROZ, T. M. de; FERREIRA, F. da S.; BENTO, T. S.; CARVALHO, M. A. C. de. Índices de satisfação de necessidade de água para o milho segunda safra em Mato Grosso. Revista Brasileira da Climatologia, Curitiba, v. 15, n. 2, p. $109-121, \quad 2015$. DOI: http://dx.doi.org/10.5380/abclima.v15i0.37309

GRIGULO, A. S. M.; AZEVEDO, V. H. de; KRAUSE, W.; AZEVEDO, P. H. de. Avaliação do desempenho de genótipos de milho para consumo in natura em Tangará da Serra, MT, Brasil. Bioscience Journal, Uberlândia, v. 27, n. 4, p. 603-608, 2011.

MORAES, A. R. A.; RAMOS JUNIOR, E. U.; GALLO, P. B.; PATERNIANI, M. E. A. G. Z.; SAWASAKI, E.; DUARTE, A. P.; BERNINI, C. S.; GUIMARÃES, P. de S. Desempenho de oito cultivares de milho verde na safrinha, no estado de São Paulo. Revista Brasileira de Milho e Sorgo, Sete Lagoas, v. 9, n. 1, p. 79-91, 2010. DOI: http://dx.doi.org/10.18512/19806477/rbms.v9n1p79-91

NASCIMENTO, F. N.; BASTOS E. A.; CARSOSO M. J.; ANDRADE JÚNIOR, A. S.; RAMOS, H. M. Desempenho da produtividade de espigas de milho verde sob diferentes regimes hídricos. Revista Brasileira de Milho e Sorgo, Sete Lagoas, v. 16, n. 1, p. 94-108, 2017. DOI: http://dx.doi.org/10.18512/19806477/rbms.v16n1p94-108

NEVES, S. M. A. S.; NUNES, M. C. M.; NEVES, R. J. Caracterização das condições climáticas de Cáceres/MT Brasil, no período de 1971 a 2009: subsídio às atividades agropecuárias e turísticas municipais. Boletim Goiano de Geografia, Goiânia, v. 31, n. 2, p. 55-68, 2011. DOI: https://doi.org/10.5216/bgg.v31i2.16845

OMETTO, J. C. Bioclimatologia vegetal. São Paulo: Agronômica Ceres, 1981. 440 p.
PAIVA, M. R. F. C.; SILVA, G. F.; OLIVEIRA, F. H. T.; PEREIRA, R. G.; QUEIROGA, F. M. Doses de nitrogênio e de fósforo recomendadas para produção econômica de milho-verde na chapada do Apodi-RN. Revista Caatinga, Mossoró, v. 25, n. 4, p. 1-10, 2012.

PINHO, L.; PAES, M. C. D.; ALMEIDA, A. C. de; COSTA, C. A. da. Qualidade de milho verde cultivado em sistemas de produção orgânico e convencional. Revista Brasileira de Milho e Sorgo, Sete Lagoas, v. 7, n. 3, p. 279-290, 2008. DOI: http://dx.doi.org/10.18512/19806477/rbms.v7n3p279-290

RENATO, N. S.; SILVA, J. B. L.; SEDIYAMA, G. C.; PEREIRA, E. G. Influência dos métodos para cálculo de graus-dia em condições de aumento de temperatura para as cultivares de milho e feijão. Revista Brasileira de Meteorologia, São Paulo, v. 28, n. 4, p. 382-388, 2013. DOI: 77862013000400004

ROCHA, R. S.; SILVA, J. A. L. da; NEVES, J. A.; SEDIYAMA, T.; CÁSSIA TEIXEIRA R. Desempenho agronômico de variedades e linhagens de soja em condições de baixa latitude em Teresina-PI. Revista Ciência Agronômica, Fortaleza, v. 43, n. 1, p. 154-162, 2012. DOI: http://dx.doi.org/10.1590/S180666902012000100019

RODRIGUES, F.; PINHO, R. G. V.; ALBUQUERQUE, C. J. B.; PINHO, E. V. R. V. Índice de seleção e estimativa de parâmetros genéticos e fenotípicos para características relacionadas com a produção de milho-verde. Ciência e Agrotecnologia, Lavras, v. 35, n. 2, p. 278-286, 2011. DOI: http://dx.doi.org/10.1590/S141370542011000200007

ROLIM, G. S.; SENTELHAS, P. C.; BARBIERI, V. Planilhas no ambiente EXCEL TM para os cálculos de balanços hídricos: normal, sequencial, de cultura e de produtividade real e potencial. Revista Brasileira de Agrometeorologia. Santa Maria, v. 6, n. 1, p 133-137, 1998.

SANTOS, P. A.; SILVA, A. F. da; CARVALHO, M. A. C. de; CAIONE, G. Adubos verdes e adubação nitrogenada em cobertura no cultivo do milho. Revista Brasileira de Milho e Sorgo, Sete Lagoas, v. 9, n. 2, p. 123-134, 2010. DOI: http://dx.doi.org/10.18512/19806477/rbms.v9n2p123-134

VIEIRA, M. A.; CAMARGO, M. K.; DAROS, E.; ZAGONEL, J.; KOEHLER, H. S. Cultivares de milho e população de plantas que afetam a produtividade de espigas verdes. Acta Scientiarum Agronomy, Maringá, v. 32 , n. $1, \quad$ p. $81-86, \quad 2010$. DOI: http://dx.doi.org/10.4025/actasciagron.v32i1.987 